\title{
Effects of sulfur-based hemostatic agents and gingival retraction cords handled with latex gloves on the polymerization of polyvinyl siloxane impression materials
}

\author{
Carlos Eduardo Palhares MACHADOํ, Carlos Gramani GUEDES ${ }^{2}$ \\ 1- Master's Degree in Health Sciences, University of Brasília, Brasília, DF, Brazil. \\ 2- PhD, Professor, Department of Dentistry, University of Brasília, Brasília, DF, Brazil.
}

Corresponding address: Carlos Gramani Guedes - Universidade de Brasília - Campus Universitário Darcy Ribeiro - Faculdade de Ciências da Saúde Departamento de Odontologia - Sala BN112 - 70910-000 - Asa Norte - e-mail: gramani@unb.br

Received: October 22, 2009 - Modification: August 26, 2010 - Accepted: October 26, 2010

\section{ABSTRACT}

\begin{abstract}
O bjectives: This study investigated the possible interactions between three addition silicone materials (Express ${ }^{\circledR}$, Aquasil Ultra ${ }^{\circledR}$ and Adsil ${ }^{\circledR}$ ), three hemostatic agents (ferric sulfate, StatGel FS ${ }^{\circledR}$; aluminum sulfate, GelCord ${ }^{\circledR}$; and aluminum chloride, Hemostop ${ }^{\circledR}$ ) and gingival retraction cords previously handled with latex gloves to determine whether direct contact with medicaments or indirect contamination by latex in conditions similar to those found in clinical practice inhibit or affect the setting of the impression materials. Material and Methods: A portable device for the simultaneous test of several specimens was specifically developed for this study. Polymerization inhibition was analyzed by examination of the impressions and the molded surface. Ten trials were performed for each addition silicone material used in the study, at a total of 240 study samples. Results: All the samples tested $(\mathrm{N}=240)$ were nonreactive regardless of the type of combination used. Conclusions: Aluminum sulfate, ferric sulfate and aluminum chloride hemostatic solutions did not show any inhibitory potential on the addition silicone samples under study, and there were no changes in polymerization as a result of contact between addition silicone and retraction cords handled with latex gloves.
\end{abstract}

Key words: Dental materials. Dental prosthesis. Polyvinylsiloxane. Latex. Hemostatic agents.

\section{INTRODUCTION}

Addition silicone stands out among impression materials because of its excellent accuracy and stability ${ }^{7}$. However, regardless of its excellent properties and widespread acceptance, it is not a perfect material ${ }^{15}$. Studies have reported on undesirable consequences of the use of this material, particularly due to its potential incompatibility with sulfur-based substances and materials ${ }^{7,8}$. Inhibitory changes have also been assigned to the contact of addition silicone with other products used in clinical dentistry, such as zinc-oxide eugenol temporary cements ${ }^{11}$, surfactants ${ }^{21}$, retraction cords contaminated with latex ${ }^{14}$ and glass-ionomer cements $^{17}$.
The direct or indirect contact with latex gloves or rubber dams seems to increase the risk of polyvinylsiloxane polymerization inhibition $5,6,9,13,16,18-20,22,25-27$, which is an important problem because latex gloves are some of the protective gear most often worn by dental professionals ${ }^{10}$.

Although scientifically confirmed, the mechanism of interaction between latex and addition silicone is not fully understood. The hypothesis more frequently accepted is that polymerization inhibition is explained by the contamination and poisoning of the metal catalyst in the addition silicone by diethyldithiocarbamate, a sulfur-containing component that is incorporated during the vulcanization of gloves and rubber dams $s^{1,4,7,8}$. 
Because of the scarcity of data to explain inhibition, some reports have disseminated a number of unproven facts about this issue, which has raised suspicions that all sulfur-containing compounds may be a potential inhibition agent when in contact with addition silicone. According to that, the possibility was raised that inhibition of polymerization of addition silicone materials may occur when in contact with sulfur-containing hemostatic solutions, such as ferric sulfate and aluminum sulfate 2,21,23.

Camargo, et al. ${ }^{3}$ (1993) evaluated the interaction of medicaments used in gingival retraction and addition silicone and found that they did not affect silicone polymerization. However, the echoes of the previous reports may still be heard today in divergent opinions about such contamination.

This study investigated the possible interactions between addition silicone materials from three different suppliers (Express ${ }^{\circledR}$, Aquasil Ultra ${ }^{\circledR}$ and Adsi ${ }^{\circledR}$ ), three hemostatic agents (ferric sulfate, StatGel FS ${ }^{\circledR}$; aluminum sulfate, GelCord ${ }^{\circledR}$; and aluminum chloride, Hemostop ${ }^{\circledR}$ ) and gingival retraction cords previously handled with latex gloves to determine whether direct contact with medicaments or indirect contamination with latex in conditions similar to those found in clinical practice inhibit or affect the setting of vinyl polysiloxane materials.

\section{MATERIAL AND METHODS}

Three different types of addition silicone, three hemostatic solutions (ferric sulfate, aluminum sulfate and aluminum chloride), latex gloves and one brand of nonimpregnated twisted gingival retraction cord were used, as described in Figure 1.

A portable device with four hollow metal cylinders fixed to an acrylic base was manufactured for the tests (Figure 2). Inside each cylinder, a piece of densely woven white cotton fabric was placed. The cloth had good absorption properties for the analysis of impression quality by observing its surface texture (Figure 2A). Each cylinder had 4 windows through which the cloth, later soaked with the different hemostatic solutions, could be examined. Around the cylinder platform there was a groove for the tests with retraction cords (Figure 2B).

In order to avoid the contamination between samples, each cylinder was used to test only one hemostatic solution: cylinder I had the aluminum sulfate samples (GelCord, Pascal International, Bellevue, WA, USA); cylinder II, the ferric sulfate samples (StatGel FS, Pascal International); cylinder III, the aluminum chloride samples (Hemostop, Dentsply Caulk, Milford, DE, USA); and cylinder IV, distilled water samples used as a control group. Distilled water was used because it is free of any salts or impurities that might inhibit silicones. Moreover, it provided a humid environment for the control group and reduced the risk of false positive results due to the direct contact of non-polymerized silicones with the dehydrated fabric.

After each impression trial, 2 tests were performed in each cylinder, so that the hemostatic solutions were tested separately in the windows on the top of the cylinder, and the retraction cords contaminated with latex, in the peripheral grooves (Figure 3A). Overall, the device could hold tests for 8 samples for each impression.

The procedures for each of the trials are described below:

The pieces of cloth were carefully positioned inside the cylinders so that they could be seen in the windows on the top of the cylinder.

Pieces of retraction cord (Roeko Retracto, Coltène/Whaledent, Langenau, BadenWürttemberg, Germany) were handled with latex gloves (Supermax Premium Quality, Supermax Glove Manufacturing SDN, Selangor, Malaysia) for $1 \mathrm{~min}$. After that, the cords were placed in Dappen dishes with hemostatic solutions and kept there for $1 \mathrm{~min}$.

The cords soaked in hemostatic solutions were placed with forceps on the grooves around the

\begin{tabular}{|c|c|c|c|}
\hline Material & Type & Batch & Manufacturer \\
\hline Express TM & Polyvinylsiloxane (Type 3 - ISO 4823) & 6 LXD1T1 & 3M ESPE Dental Products, St. Paul, USA \\
\hline Aquasil Ultra & Polyvinylsiloxane (Type 3 - ISO 4823) & 60920 & Dentsply Caulk, Milford, USA \\
\hline Adsil & Polyvinylsiloxane (Type 2 - ISO 4823) & 706 & Vigodent S/A, Rio de Janeiro, Brazil \\
\hline Stat-Gel FS & 15.5\% Ferric Sulfate Gel & 80109 & Pascal International, Bellevue, USA \\
\hline GelCord & 25\% Aluminium Sulfate Gel & 120108 & Pascal International, Bellevue, USA \\
\hline Hemostop & Aluminium Chloride & 745830 & Dentsply Caulk, Milford, USA \\
\hline $\begin{array}{c}\text { Supermax Premium } \\
\text { Quality }\end{array}$ & Latex Gloves & 63723316 & $\begin{array}{c}\text { Supermax Glove Manufacturing SDN, } \\
\text { Selangor, Malaysia }\end{array}$ \\
\hline Roeko Retracto & Non Impregnated Twisted Cord \#2 & 107240 & Coltène/Whaledent, Langenau, Germany \\
\hline
\end{tabular}

Figure 1- Materials used in the study 
cylinder according to the type of solution tested:

Hemostatic solutions were dispensed into the cylinders using brushes until saturation was visually

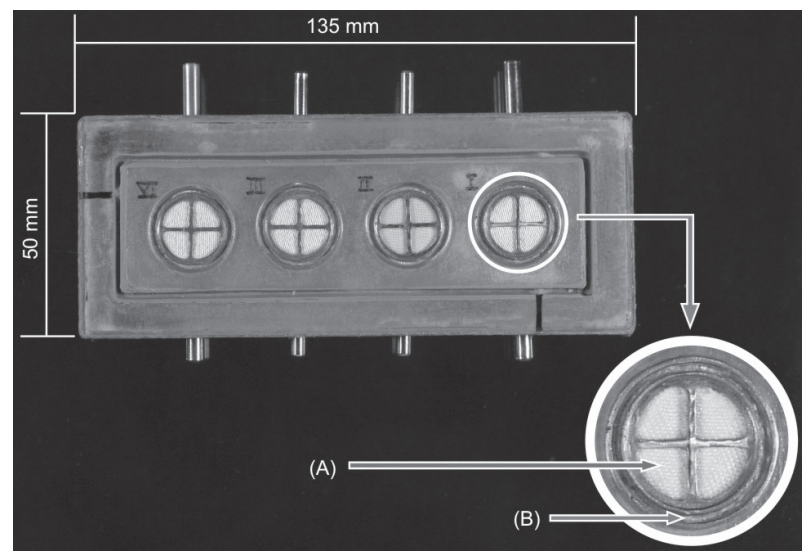

Figure 2- Top view of device used in tests, made up of 4 cylinders that held the pieces of cloth. In the lower righthand corner, detail of metal cylinder. The A arrow points to piece of cloth seen in the four windows of the central area of the cylinder; the $B$ arrow points to the peripheral groove where the retraction cords were tested confirmed in the cloth weave (Figure 3A). Care was taken not to let it touch the area that held the retraction cord.

Addition silicone was dispensed on the cylinders in circular movements using a dispensing gun and mixing tips. The impression material was dispensed into the cylinders within the working time recommended by the manufacturers of the addition silicones under study, and all trials were conducted in a room where the temperature was controlled at $20^{\circ} \mathrm{C}$ (Figure 3B).

Removal from the mold was 7.5 min after impression of the last cylinder, which is sufficient time for setting of all materials tested according to the manufacturers' recommendations (Figure 3C).

The latex gloves, the pieces of cloth, and the pieces of retraction cord, as well as the hemostatic solutions, were replaced for each new trial. Ten trials were performed for each addition silicone brand used in the study, totalizing 240 samples (Figure 4).

Polymerization inhibition was detected according to the surface analysis of the impression and the molded surface, described in the literature as a simple, practical and very efficient form to visualize inhibition in addition silicone materials ${ }^{11,12,24}$. When

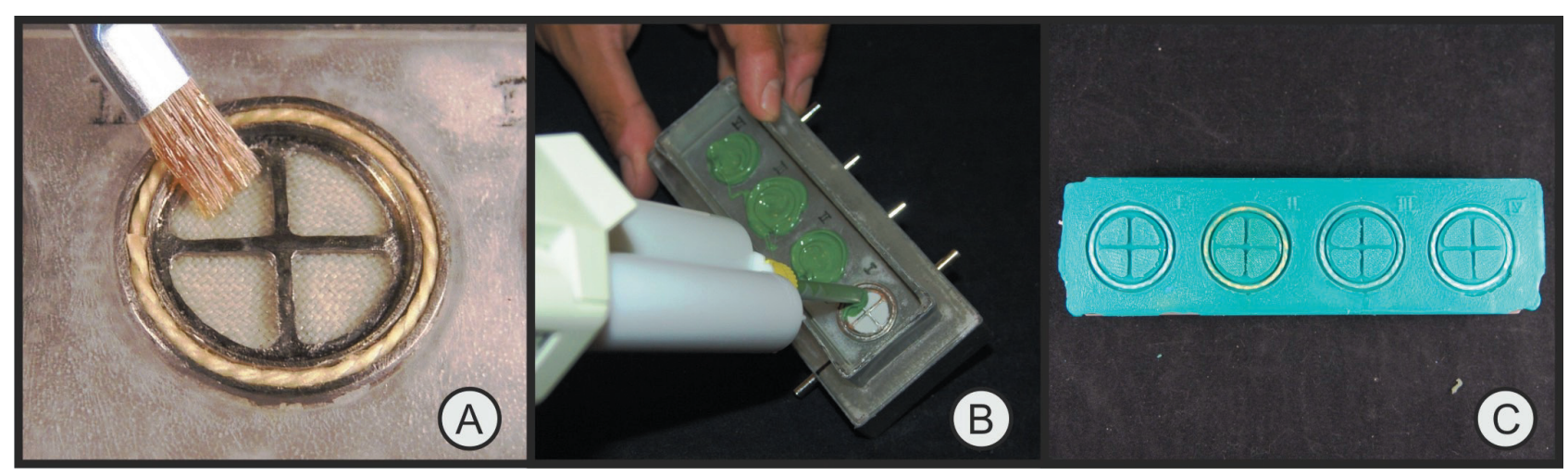

Figure 3- Sequence (A, B and C) of procedures for each impression trial

\begin{tabular}{|c|c|c|c|c|c|}
\hline \multirow[b]{2}{*}{ Material tested } & \multirow[b]{2}{*}{ Cylinder } & \multicolumn{3}{|c|}{$\begin{array}{l}\text { Number of samples }(n) \text { according to } \\
\text { impression material }\end{array}$} & \multirow[b]{2}{*}{ TOTAL } \\
\hline & & Adsil & Aquasil Ultra & Express & \\
\hline Aluminum sulfate & 1 & 10 & 10 & 10 & 30 \\
\hline Ferric sulfate & II & 10 & 10 & 10 & 30 \\
\hline Aluminum chloride & III & 10 & 10 & 10 & 30 \\
\hline Distilled water (control) & IV & 10 & 10 & 10 & 30 \\
\hline Retraction cord ${ }^{*}+$ Aluminum sulfate & 1 & 10 & 10 & 10 & 30 \\
\hline Retraction cord ${ }^{*}+$ Ferric sulfate & II & 10 & 10 & 10 & 30 \\
\hline Retraction cord ${ }^{*}+$ Aluminum chloride & III & 10 & 10 & 10 & 30 \\
\hline Retraction cord $^{*}+$ Distilled water (control) & IV & 10 & 10 & 10 & 30 \\
\hline Total number of specimens tested & & 80 & 80 & 80 & 240 \\
\hline
\end{tabular}

${ }^{*}$ Retraction cords that had been handled with latex gloves before tests.

Figure 4- Summary of tests performed during the study 
signs of inhibition were found, the material was classified as reactive. If no signs were found, the material was classified as nonreactive. The signs of inhibition are listed below:

1 - Residues of nonpolymerized material (oily substance) on the surface of the impression and support;

2- Rugosity of the impression surface; and,

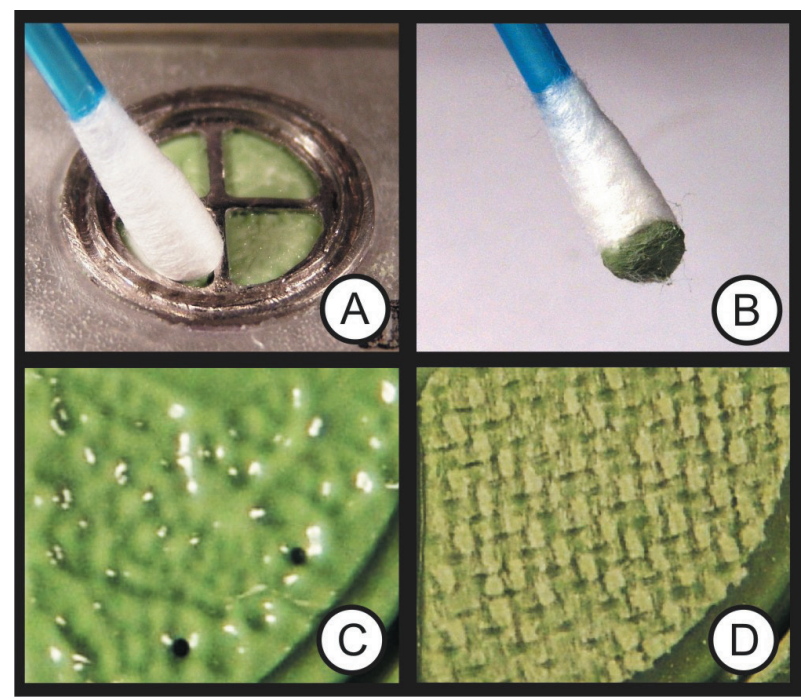

Figure 5- A and B show the effectiveness of the method used to detect residues of polymerized material on the surface of the piece of fabric and the impression; the color difference between the cotton tip and the residues of nonpolymerized material clearly indicate the occurrence of inhibition. $C$ and $D$ show the difference between a surface with incomplete (C) and complete (D) polymerization. C shows surface undulations and oiliness on impression, which resulted from polymerization caused by the direct contact with latex (used in previous tests). D shows complete polymerization, in which the material reproduces the fabric weave accurately
3- Lack of detail reproduction on the surface of the impression.

The analysis of nonpolymerized material residues that adhered to the surface was made using cotton tips that were rubbed onto the surface that had been in contact with the hemostatic solutions. The same method was used for the detection of residues adhered to the surface of the pieces of cloth. Residues or oiliness, when found, was easily detected by observing the dies that adhered to the fabric surface, which was in contrast with the white surface (Figure 5A/B). The texture of the impression surface and its capacity to reproduce details were analyzed using close-up photographs (Figure 5C/D) and material scraping with smooth-tipped instrument. In cases of inhibition, it was possible to see undulations on the impression surface, and material could be removed by scraping.

To analyze polymerization in the area of contact with the retraction cords, a small caliber instrument was used for scraping. The test result was negative when visual inspection did not reveal residues of nonpolymerized material (oiliness) on the impression surface. The retraction cords used in each test were also inspected. For this purpose, cotton tips were rubbed against the cord surface after they were removed from their grooves. A third method to detect changes in polymerization due to the contact with contaminated cords was the evaluation of the capacity of the impression material to reproduce form and surface texture. The material should be capable of reproducing the weave of the twisted cords faithfully.

\section{RESULTS}

Figure 6 shows the number of reactive and nonreactive samples according to type of addition silicone used ( $N=10 /$ silicone type). These data

\begin{tabular}{|c|c|c|c|c|c|c|c|c|}
\hline Material tested & \multicolumn{2}{|c|}{ Adsil } & \multicolumn{2}{c|}{ Aquasil Ultra } & \multicolumn{2}{c|}{ Express } & \multicolumn{2}{c|}{ TOTAL } \\
\hline & Reactive & $\begin{array}{c}\text { Non } \\
\text { reactive }\end{array}$ & Reactive & $\begin{array}{c}\text { Non } \\
\text { reactive }\end{array}$ & Reactive & $\begin{array}{c}\text { Non } \\
\text { reactive }\end{array}$ & Reactive & $\begin{array}{c}\text { Non } \\
\text { reactive }\end{array}$ \\
\hline Aluminum sulfate & 0 & 10 & 0 & 10 & 0 & 10 & $0(0 \%)$ & $30(100 \%)$ \\
\hline Ferric sulfate & 0 & 10 & 0 & 10 & 0 & 10 & $0(0 \%)$ & $30(100 \%)$ \\
\hline Aluminum chloride & 0 & 10 & 0 & 10 & 0 & 10 & $0(0 \%)$ & $30(100 \%)$ \\
\hline Distilled water (control) & 0 & 10 & 0 & 10 & 0 & 10 & $0(0 \%)$ & $30(100 \%)$ \\
\hline Cord +Aluminum sulfate & 0 & 10 & 0 & 10 & 0 & 10 & $0(0 \%)$ & $30(100 \%)$ \\
\hline Cord*+Ferric sulfate & 0 & 10 & 0 & 10 & 0 & 10 & $0(0 \%)$ & $30(100 \%)$ \\
\hline Cord*+Aluminum chloride & 0 & 10 & 0 & 10 & 0 & 10 & $0(0 \%)$ & $30(100 \%)$ \\
\hline Cord + Distilled water (control) & 0 & 10 & 0 & 10 & 0 & 10 & $0(0 \%)$ & $30(100 \%)$ \\
\hline TOTAL & 0 & 80 & 0 & 80 & 0 & 80 & $0(0 \%)$ & $240(100 \%)$ \\
\hline
\end{tabular}

*Retraction cords that had been handled with latex gloves before tests.

Figure 6- Results of tests in number of samples $(\mathrm{N})$ 
show that all the samples tested $(N=240)$ were nonreactive regardless of the type of combination used. No residues of nonpolymerized material adhered to the surfaces in any of the impressions or pieces of fabric. Scraping tests were also negative for all samples. There was perfect reproduction of the fabric weave in all hemostatic solution groups, as well as of the retraction cord fibers contaminated by contact with latex gloves, which can be confirmed in Figure 7.

No statistical analyses were conducted because all tests were negative for $100 \%$ of the samples tested.

\section{DISCUSSION}

One of the main uses of hemostatic agents in combination with retraction cords is to control humidity and bleeding from the gingival sulcus during impression, so that a usually hydrophobic material may faithfully reproduce the details of tooth preparation ${ }^{3}$. Therefore, this type of solution should be compatible with the material that will be used in reproducing oral structures. However, aluminum sulfate and ferric sulfate used as hemostatic solutions, due to the presence of the sulfur radical in their molecular structure, raised the suspicion that they might inhibit polymerization of polyvinyl, such as in the case of sulfur incorporated during the process of vulcanization of latex gloves. Therefore, by analogy, sulfur found in the sulfate radicals was thought to interact with the catalytic sites of addition silicone materials and to block setting.

Although these suspicions were serious and involved sulfur solutions, few authors studied it directly. One of the few studies to focus on this subject evaluated several solutions, including ferric and aluminum sulfates, and found that they did not have any inhibitory potential on silicone materials ${ }^{3}$. There were suggestions that clinical reports to the contrary might be better explained by contamination with latex found in gloves rather than by the medicaments used for gingival retraction. The results of our study are in agreement with those findings because silicone materials were nonreactive to the hemostatic solutions tested here.

The reason why sulfur solutions did not react in the polymerization of polyvinylsiloxane materials may be explained by the molecular position of sulfur atoms. The molecular analyses of these solutions show that the sulfur in their composition is in a state different from the one found in the latex gloves, whose inhibition potential has already been confirmed in the literature ${ }^{1,4,7,8}$. Sulfur in the sulfate solutions, contrarily to that found in latex gloves, has greater electrical stability, saturated by oxygen atoms, less reactive, and, therefore, incapable of reacting with metal catalysts ${ }^{8}$. For this reason, the mere presence of sulfur does not give the material any inhibitory properties. To find out whether a substance has any inhibition potential, direct inhibition tests ${ }^{18}$ or molecular analysis of the compound should be performed to provide indications about the degree of reaction of the element of interest.

After the confirmation of the inhibitory effects of the direct contact between polyvinylsiloxane and products containing latex, studies about indirect contamination became important in the literature referring to addition elastomers. The principles of "indirect contamination" or "crossed contamination" reside in the fact that all contact between two surfaces or materials is followed by exchanges of substances between them, even if only at a molecular level. To confirm this principle, the dental literature has already demonstrated that sulfurous materials may be exchanged between latex gloves and the structures exposed to the gloves, such as teeth, soft tissues, gingival retraction cords and dental office instruments ${ }^{5,9,12-14}$. According to other authors, the sulfur transferred, in some cases, would produce the same inhibitory effects triggered by the latex gloves.

The inhibitory potential of indirect latex contamination should not be downplayed. In a previous study, the chemical analysis of the surface of vinyl gloves and gingival retraction cords, both contaminated by latex gloves, showed that sulfur particles and sulfur chloride compounds were found in all the samples analyzed. For the authors of that study, those particles should be able to interfere in polyvinylsiloxane polymerization ${ }^{14}$. Another study evaluated the inhibition of addition silicone polymerization by direct and indirect contact with latex gloves and found that $96 \%$ of the gloves tested inhibited silicone polymerization by direct contact and $40 \%$ by direct and indirect contact, which is a contraindication for their use when handling these materials.

Despite the several findings reported in the literature, the results of the present study did not show inhibition of polymerization in any of the polyvinylsiloxane samples that were exposed to contact with retraction cords previously handled with latex gloves. On the contrary, the elastomeric material reproduced the cord texture accurately in all samples $(\mathrm{N}=120)$, and there was no sign of inhibition or retarded setting detected by visual analysis of the impressions or pieces of fabric. It may be inferred that the cord surfaces had sulfur particles that would contaminate the silicone catalyst ${ }^{14}$; however, the low concentration of this element seems to have been insufficient to trigger any inhibition that may be perceived by the methods used in this study. 
The presence of reactive sulfur on the surface of the cords ${ }^{14}$ suggests that some type of change in polymerization may have occurred in practice, but was subclinical, and its detection using visual methods was either too complex or impossible. If this method were used in a clinical context, an equally complicated situation would arise, in which the dentist would be incapable of detecting inhibitory effects of the contaminated cord because the phenomenon tends to occur at levels that are beyond visual detection. Therefore, as the purpose of this study was to conduct an analysis according to clinical and visual criteria, it is possible to assume that, in the study samples, the inhibitory potential of the cords indirectly contaminated by latex, although present and important, did not produce clinically relevant effects.

\section{CONCLUSION}

According to the study methods, it may be concluded that:

Aluminum sulfate, ferric sulfate and aluminum chloride hemostatic solutions did not show any inhibitory potential over the addition silicone materials under study.

There were no visual changes in polymerization in consequence of the contact between silicone materials and the cords handled with latex gloves.

Further studies should be conducted using more sensitive methods to address the possible disadvantages of the subclinical inhibition of polyvinylsiloxane polymerization.

\section{REFERENCES}

1- Baumann MA. The influence of dental gloves on the setting of impression materials. Br Dent J. 1995;179:130-5.

2- Burmann PA, Cardoso PE. Moldagem com silicone de reação por adição Aquasil: a otimização da moldagem ao alcance do Clínico. Clinical Update Dentsply [serial on the Internet]. 2002 [cited on 19 jan 2011];3:1-8. Available from: URL: <http://www.dentsply. com.br/isogesac/imgcatalogo/clinical3_aquasildentística.pdf > 3- Camargo LM, Chee WW, Donovan TE. Inhibition of polymerization of polyvinyl siloxanes by medicaments used on gingival retraction cords. J Prosthet Dent. 1993;70:114-7.

4- Causton BE, Burke FJ, Wilson NH. Implications of the presence of dithiocarbamate in latex gloves. Dent Mater. 1993;9:209-13.

5- Chee WW, Donovan TE, Kahn RL. Indirect inhibition of polymerization of a polyvinyl siloxane impression material: a case report. Quintessence Int. 1991;22:133-5.

6- Cook WD, Thomasz F. Rubber gloves and addition silicone materials. Aust Dent J. 1986;31:140.
7- Donovan TE, Chee WW. A review of contemporary impression materials and techniques. Dent Clin N Am. 2004;48:445-70.

8- Dunleavy JK. Sulfur as a catalyst poison. Platinum Metal Ver. 2006;50:110.

9- Fan PL. Retarding the setting of vinyl polysiloxane impressions. J Am Dent Assoc. 1991;122:114.

10- Gnaneswaran V, Mudhunuri B, Bishu RR. A study of latex and vinyl gloves: performance versus allergy protection properties. Int J Ind Ergonom. 2008;38:171-81.

11- Jones RH, Cook GS, Moon MG. Effect of provisional luting agents on polyvinyl siloxane impression material. J Prosthet Dent. $1996 ; 75: 360-3$

12- Kahn RL, Donovan TE. A pilot study of polymerization inhibition of poly (vinyl siloxane) materials by latex gloves. Int J Prosthodont. 1989;2:128-30.

13- Kahn RL, Donovan TE, Chee WW. Interaction of gloves and rubber dam with poly(vinyl siloxane) impression material: a screening test. Int J Prosthodont. 1989;2:342-6.

14- Kimoto K, Tanaka K, Toyoda M, Ochiai KT. Indirect latex gloves contamination and its inhibitory effect on vinyl polysiloxane polymerization. J Prosthet Dent. 2005;93:433-8.

15- Mandikos MN. Polyvinyl siloxane impression materials: an update on clinical use. Aust Dent J. 1998;43:428-34.

16- Matis BA, Valadez D, Valadez E. The effect of the use of dental gloves on mixing vinyl polysiloxane putties. J Prosthodont. 1997;6:189-92.

17- Moon MG, Jarrett TA, Morlen RA, Fallo GJ. The effect of various base/core materials on the setting of a polyvinyl siloxane impression material. J Prosthet Dent. 1996;76:608-12.

18- Neissen LC, Strassler H, Levinson PD, Wood G, Greenbaum J. Effect of latex gloves on setting time of polyvinylsiloxane putty impression material. J Prosthet Dent. 1986;55:128-9.

19- Noonan JE, Goldfogel MH, Lambert RL. Inhibited set of the surface of addition silicones in contact with rubber dam. Oper Dent. $1985 ; 10: 46-8$.

20- Peregrina A, Land MF, Feil P, Price C. Effect of two types of latex gloves and surfactants on polymerization inhibition of three polyvinylsiloxane impression materials. J Prosthet Dent. 2003;90:289-92.

21- Phillips RW. Skinner's science of dental materials. Phyladelphia: WB Saunders; 1991. p. 154.

22- Reitz CD, Clark NP. The setting of vinyl polysiloxane and condensation silicone putties when mixed with gloved hands. J Am Den Assoc. 1988;116:371-5.

23- Sábio S, Franciscone PA, Mondelli J. Effect of conventional and experimental gingival retraction solutions on the tensile strength and inhibition of polymerization of four types of impression materials. J Appl Oral Sci. 2008;16:280-5.

24- Touyz LZ, Rosen M. The effect of maize starch on setting time of vinyl polysiloxane putty impression materials. J Dent Assoc S Afr. 1989;44:377-9.

25- Vinyl polysiloxane impressions materials: a status report. Council on Dental Materials, Instruments, and Equipment. J Am Dent Assoc. 1990;120:595-600.

26- Welfare RD. Problems with addition-cured silicone putty, letter to the editor. Br Dent J. 1986;160:268-9.

27- White N. The effect of latex gloves on setting time of vinyl polysiloxane putty impression material. Br Dent J. 1989;167:51. 